\title{
The role of magnesium sulphate in the management of Irukandji Syndrome: A Systematic Review
}

Authors:

John Rathbone BHIthSc (Paramedic) ${ }^{1,2}$. Richard Franklin PhD, FPHAA, FARLF ${ }^{2,3}$ Clinton Gibbs MBBS, FACEM, DipDHM, PGCertAeromed.Ret ${ }^{4,5,6}$. David Williams ${ }^{7}$ BSc, GDip, PhD.

Affiliations

1: Queensland Ambulance Service, Townsville QLD, Australia.

2: College of Public Health, Medical and Veterinary Science, James Cook University, Townsville QLD, Australia

3. Royal Life Saving Society - Australia

4. Emergency Department, The Townsville Hospital, Townsville Hospital and Health Service, Queensland Health

5. Retrieval Services Queensland, Aeromedical Retrieval and Disaster Management Branch Prevention Division, Queensland Health

6. College of Medicine and Dentistry, James Cook University

7. Australian Venom Research Unit, Department of Pharmacology and Therapeutics, University of Melbourne, Parkville, VIC., 3010. Australia

Contact details:

John Rathbone

College of Public Health, Medical and Veterinary Sciences

Public Health and Tropical Medicine

Townsville, Qld Australia 4811

Ph: +61400259232

E-mails: John.Rathbone@ambulance.qld.gov.au

\section{Author's contribution:}

This is the author manuscript accepted for publication and has undergone full peer review but has not been through the copyediting, typesetting, pagination and proofreading process, which may lead to differences between this version and the Version of Record. Please cite this article as doi: $10.1111 / 1742-6723.12694$

This article is protected by copyright. All rights reserved. 
$J R$ and RF conceived of the idea, JR and RF developed the methodology, JR and RF undertook the initial review of the papers, all authors review the final papers, JR undertook the first draft, all authors contributed to final draft.

\section{Introduction}

Irukandji Syndrome (IS) came to the public attention with the report of the deaths of two tourists in $2002^{1,2}$ attributed to a small box jellyfish in tropical Queensland, Australia. Both fatalities were attributed to a hypertensive induced cerebral haemorrhage, stressing the importance of controlling the acute hypertensive state that can arise in some cases of this painfully debilitating marine envenomation ${ }^{3}$. This reduction could also reduce the likelihood of the patient developing cardiac dysfunction.

In 1961 Dr Jack Barnes identified two small carybdeid specimens that caused IS ${ }^{3}$. In honour of Jack Barnes, Southcott named the carybdeid Carukia barnesi ${ }^{4}$.

To date there are nine Australian species of carybdeid that have been formally identified that cause $1 \mathrm{~S}^{5}$. Even though this syndrome was first recognized in Australia, there have been reports of IS elsewhere across the globe, Hawaii ${ }^{6}$, Thailand ${ }^{7}$, Florida $^{8}$, Philippines ${ }^{9}$, even in the cool waters of Northern Wales, UK ${ }^{10}$ and Victoria, Australia ${ }^{11}$. Most of the species held responsible are still yet to be formally identified, and therefore IS refers to a group of systemic symptoms resulting from a carybdeid sting.

Fenner ${ }^{12}$ and Carrette ${ }^{13}$ describe in detail the signs and symptoms of IS. The initial sting from the jellyfish is likely to be innocuous with minimal contact symptoms and indeed some individuals not noticing it at all, while species such as Malo maxima from Western Australia and Morbakka fenneri from Queensland cause immediate notable pain upon contact ${ }^{14}$. There is a delay before the onset of systemic symptoms from 5 to 120 minutes ( $n=30$ minutes) ${ }^{15}$ after which the patient begins to experience systemic pain.

There may be minimal skin markings with localized piloerection and sweating, but this often goes unnoticed. Systemic symptoms can range from; low back pain, limb muscle/cramping pain, chest pain/tightness, sweating (localized or general), piloerection (localized or general), anxiety/feeling of impending doom, restlessness, headache, nausea, vomiting, increased respiratory rate, tremor, pallor, oliguria, tachycardia and hypertension ${ }^{12}$. The symptoms of IS resemble that of a hyperadrenergic state and in animal modelling with crude Carukia barnesi venom, shows gross elevation in systemic noradrenaline and adrenaline, 200 -fold \& 100 -fold respectively ${ }^{16}$.

Occasionally a 'second phase' may appear in severe cases of IS. These patients appear to develop severe hypertension with pressures as high as $300 / 180 \mathrm{mmHg}$ being recorded ${ }^{12}$. 
Approximately 6-18 hours after the sting, patients can develop pulmonary oedema, which may be associated with depressed ejection fraction, reduced cardiac output and raised serum cardiac enzymes ${ }^{12,14}$. The two documented fatalities attributed to IS have both been off shore stings, GBR and Whitsunday Islands, and both were due to intracranial hemorrhages, presumed secondary to severe hypertension ${ }^{1,2}$. The first a 58 year old male stung in the Whitsunday Islands, who developed critical hypertension $(260 / 160 \mathrm{mmHg})$ and had a raised troponin $\mathrm{T}(27 \mathrm{ug} / \mathrm{L}$ ). This gentleman had an extensive medical history including an aortic valve replacement due to aortic stenosis, he was taking $8 \mathrm{mg}$ warfarin daily and a week prior to the incident he had an international normalized ratio (INR) of $5.0^{1}$. The second was a 44 year old male was stung on the GBR who also developed critical hypertension $(230 / 90 \mathrm{mmHg})$ and had a raised troponin $\mathrm{T}(34 \mathrm{ug} / \mathrm{L})^{2,14}$.

The administration of Magnesium Sulphate $\left(\mathrm{MgSO}_{4}\right)$ for the treatment of hyperadrenergic conditions, such as phaeochromocytoma, pre-eclampsia but also in cardiology and asthma is a well-established therapy ${ }^{17}$. $\mathrm{MgSO}_{4}$ has not only a depressant effect on the release of systemic catecholamines but is also known to produce a fall in systemic vascular resistance in hyperadrenergic settings ${ }^{17}$. However, magnesium toxicity can develop when serum concentrations exceed $1.74-2.61 \mathrm{mmol} / \mathrm{L}$ leading to nausea, vomiting, facial flushing, hypotension, urinary retention, ileus, lethargy and eventually muscle weakness, shortness of breath, arrhythmias and cardiac arrest ${ }^{18}$. Based on this premise and his extensive experience in managing severe pre-eclampsia, Corkeron ${ }^{19}$ reported the successful use of $\mathrm{MgSO}_{4}$ in a 26 year old male diagnosed with IS. Although this patient had previously received morphine and diazepam which had 'settled his pain somewhat', he was still profusely diaphoretic, agitated and had continued abdominal discomfort. In the setting of persistent hypertension $(170 / 100 \mathrm{mmHg})$, it was decided to start a therapeutic trial of $\mathrm{MgSO}_{4}$ Some 5 hours after the envenomation. A loading dose of $10 \mathrm{mmol} \mathrm{MgSO}_{4}$ was given, followed immediately by an infusion of $5 \mathrm{mmol}$ per hour. Towards the end of the initial loading dose, it was reported that the patient had resolution of systemic symptoms, agitation and pain had nearly subsided ${ }^{19}$.

There is, however, controversy over the use of $\mathrm{MgSO}_{4}$ in the management of IS, and some physicians and research scientists recommend the use of $\mathrm{MgSO}_{4}$ needs to be reconsidered until there is good evidence to support this ${ }^{20}$. In order to evaluate the evidence base we have conducted a critical review of the literature, focusing on the data which either supports or contraindicates the effectiveness of the use of $\mathrm{MgSO}_{4}$ in the treatment of pain and/or hypertension among patients with IS, and whether or not successful use has been dose-dependent. 


\section{Aims}

The aim of this study was to explore the literature on the effectiveness of the use of magnesium in the treatment of pain and/or hypertension in the setting of IS, and whether it's partial success has been dosage dependent.

\section{Methods}

Articles relevant to IS and the use of magnesium were collected from three data bases; Scopus, Medline and ScienceDirect. Each data base was searched using the word 'Irukandji', the returned result was then searched again using the word 'magnesium'. A further hand search was conducted both of the references of the papers and through Google Scholar for citing papers. Also a search of Google Scholar for the words 'irukandji and magnesium' was also undertaken.

There were 177 results identified and entered into EndNote $X 7^{\mathrm{TM}}$ (Thomson Reuters, New York), duplicates removed and then reviewed firstly via title description, then abstracts, and finally reading the whole paper. All searches were conducted on the 2nd March 2014 with no date restrictions. This resulted in a total of nine papers (Figure 1)

[Insert Figure 1 about here]

Only nine were identified as to having sufficient detail to be included in the systematic review. Inclusion was based on having information regarding the dose and method of administration of $\mathrm{MgSO}_{4}$ and/or patients outcomes such as: reduction in pain and/or blood pressure or the recurrence of pain and/or other symptoms; after its administration.

The methodological quality level evidence of the eight articles was reviewed with reference to the Australian Resuscitation Council evidence-based guidelines ${ }^{21}$ (Table 1).

\section{Results}

There were nine papers included in the review (Table 2). Of these, one article (RCT) does not support the use $\mathrm{MgSO}_{4}$ until further evidence supports its benefit ${ }^{20}$, another reports its failure based upon anecdotal evidence ${ }^{22}$, whilst the remaining seven ${ }^{19,23-28}$, which are case series, report some success in managing IS with $\mathrm{MgSO}_{4}$. 
[Insert Table 2 about here]

Articles supportive or negative for the use of $\mathrm{MgSO}_{4}$ in the management of pain and or hypertension in IS are listed in the Table 3 according to the ARC Methodological Quality of Studies. (REFERENCE)

[Insert Table $1 \& 3$ about here]

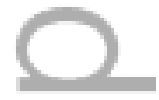

In 2004 a group from several medical centers in Northern Australia reported success in managing IS with $\mathrm{MgSO}_{4}$ in a case series of ten patients. No standardized dosing regimen for $\mathrm{MgSO}_{4}$ was prescribed although dose range was recommended on the current management of pre-eclampsia. Of the ten patients, five had marked reduction in pain during the initial loading dose, and one reported minor pain which was augmented with a further $10 \mathrm{mmol}$ bolus. The remaining four had the word 'improved' documented on their charts. Two patients with serious symptoms initially (pain scores of ten), had pain reduction to three and four respectively with bolus therapy, but required opiate therapy during the maintenance phase of $\mathrm{MgSO}_{4}$ due to the recurrence of pain ${ }^{23}$. They also noted a modest but significant reduction in systolic and mean arterial blood pressure after the administration of $\mathrm{MgSO}_{4}$, with a mean difference of -18.1 and $-18.0 \mathrm{mmHg}$ respectively ${ }^{23}$. Four patients reported pain upon injection. However, one patient who had received a total of $166 \mathrm{mmol} \mathrm{MgSO}_{4}$ over an 18 hour period, had evidence of ptosis and diplopia which resolved once the infusion was withdrawn.

Little ${ }^{22}$ reported two cases from Broome, Western Australia (WA) were $\mathrm{MgSO}_{4}$ failed. It appears that one of those patients seems to have had some initial success with $\mathrm{MgSO}_{4}(20$ $\mathrm{mmol}$ Bolus, $10 \mathrm{mmol} /$ hour infusion) but experienced a breakthrough in pain, requiring further management with opiate analgesics. The second patient continued to experience an increase in pain despite the use of $\mathrm{MgSO}_{4}$ (16 mmol bolus and $4 \mathrm{mmol} /$ hour infusion) ${ }^{22}$. These two patients required further significant pain management with opiates after receiving $\mathrm{MgSO}_{4}$, Eventually both patients required intubation and ventilation with the second patient developing pulmonary oedema, hypotension and raised troponin $(0.4 \mu \mathrm{g} / \mathrm{l}$ : normal $<0.1 \mu \mathrm{g} / \mathrm{l})$. Macrokanis briefly reports the initial success of $\mathrm{MgSO}_{4}$ in three cases from Broome, WA, in all three patients there was significant pain reduction within minutes of receiving $\mathrm{MgSO}_{4}$, from 10 to less than 5. Although $\mathrm{MgSO}_{4}$ infusions was established, all three patients reported the reoccurrence of pain between 15 and 35 minutes $^{24}$. It also mentions a further seven cases that improved without the use of $\mathrm{MgSO}_{4}$. A case series of eight patients was reported from the Torres Strait Islands, Queensland in 2011, with one 
patient receiving MgSO4 as an infusion post opiate management. Details on dosage and infusion duration are not available but the author's state that the patient had improvement in pain but remained hypertensive ${ }^{25}$. Of the eight patients, four were discharged the same day, whilst the remainder were discharged the following day. Nickson ${ }^{26}$ also reported three cases from the Northern Territory that had initial success during the loading phase but experienced pain break through during the infusion stage of $\mathrm{MgSO}_{4}$. One of those patients required further administration of morphine (10 mg IV during the next $7 \mathrm{~h}$ ), whilst a second patient received further $\mathrm{MgSO}_{4}\left(10 \mathrm{mmol}\right.$ IV during $2 \mathrm{~h}$ ) when pain recurred at $20 \mathrm{~h}^{26}$. A clinical practice update from the Townsville Hospital Emergency Department lists in detail their current management plan for the care of patients with $\mathrm{IS}^{28}$. The Emergency Department identified a total of 15 cases of IS from Jan 2006 and Dec 2008. Of those, twelve were given $\mathrm{MgSO}_{4}$, two of which were given $\mathrm{MgSO}_{4}$ as a first line treatment. The article reports that in all twelve cases there was improvement in the patient's pain and or blood pressure.

From November 2003 to May 2007 a group based in Cairns Hospital (CH) ran a double blinded randomized controlled trial with $\mathrm{MgSO}_{4}$ in the treatment of IS. Over this period a total of 121 patients were treated for IS in the CH Emergency Department (ED), of which 39 patients were recruited into the trial ${ }^{20}$. The trial concludes that there appears to be no beneficial difference in those patients that received the $\mathrm{MgSO}_{4}$ with those who received the placebo. Although upon receiving $\mathrm{MgSO}_{4}$ one patient developed tachycardia (125 bpm), flushing and sweating during the initial dose. Four further patients who received $\mathrm{MgSO}_{4}$ went on to develop pulmonary oedema, compared with none receiving saline. Four patients receiving $\mathrm{MgSO}_{4}$ and one who received the placebo were admitted to the $\mathrm{CCU}$ due to their clinical condition. The study model demonstrated that there was no significant difference between the placebo group and those that received $\mathrm{MgSO}_{4}$. See Table 4 for Summary..

Insert Table 4 about here

The study excluded more patients than that were enrolled; 21 patients being less than 16 years (RCT min age); 13 received no opiates prior to arrival at ED; 18 due to staff not being available; and 30 having to be excluded due to them receiving $\mathrm{MgSO}_{4}$ prior to their arrival in ED. $\mathrm{MgSO}_{4}$ dosage was based on Corkeron ${ }^{22}$ original description, with a $10 \mathrm{mmol}$ bolus followed by a $5 \mathrm{mmol} /$ hour infusion for 6 hours ${ }^{20}$. The largest published series regarding the use of $\mathrm{MgSO}_{4}$ in IS comes from Rathbone ${ }^{27}$, describing the use of a specific protocol of $\mathrm{MgSO}_{4}$ for the pre-hospital management of IS by Queensland Ambulance Service (QAS).In their protocol, $\mathrm{MgSO}_{4}$ is administered if the initial use of parenteral opiates has not resulted in clinically adequate analgesia. Their adult dosing is a $20 \mathrm{mmol}$ bolus followed by infusion 
of $20 \mathrm{mmol} /$ hour. In children, a $0.1 \mathrm{mmol} / \mathrm{kg}$ bolus dose is given over ten minutes, and is repeated once if required (total max dose $10 \mathrm{mmol}$ ), but no infusion is administered ${ }^{30}$.

From 2007 to 2011, fifty four patients in Queensland were treated with combined opiate analgesia and $\mathrm{MgSO}_{4}$ therapy by QAS. Their results suggest that the combination of opiate and $\mathrm{MgSO}_{4}$ demonstrate a degree of efficacy in pain management and hypertension. Three patients alone with initial pain scores of $10 / 10$ recorded no pain post administration of the loading dose. Of the 54 patients reviewed, 33 were initially hypertensive. Of these 33, 17 returned to normotensive, 9 were considered to be still hypertensive but had a reduction in their blood pressure and had no change at all upon their arrival at the receiving hospital, ${ }^{27}$. The published letter has limited data for analysis and all patients received morphine prior to receiving $\mathrm{MgSO}_{4}$, leaving the question of whether it was the opiate, $\mathrm{MgSO}_{4}$ or a combination of the both that gave the end results

\section{Discussion}

This systematic review found insufficient evidence to support any clear recommendation regarding the use of magnesium but nor was there clear evidence to recommend against its use in Irukandji envenoming. It was also inconclusive in determining whether the partial success of magnesium has been dosage dependent. A large number of papers were excluded due to a lack of discussion regarding the use of $\mathrm{MgSO}_{4}$, and due to insufficient details regarding patient's condition, their treatment and outcomes.

Overall the evidence for or against is weak with all studies bar one being case series. The single RCT undertaken in this area found no difference in analgesia requirements but it is a small trial of limited recruitment and methodological challenges. The authors note the limitations of the study; the magnesium dose during the trial was less than the now recommended dose given by the Irukandji Taskforce ${ }^{29}$; pain scores were not always collected; classifying the severity of the syndrome is difficult and it is possible that the two groups had different severities of the syndrome. There is also the high patient exclusion criteria, only 39 of a possible 121 patients were recruited into the trial. Unfortunately the study had to be terminated early as QAS and other health care providers adopted the use of $\mathrm{MgSO}_{4}$ for IS in 2006 (during the trail) ${ }^{28}$. The early termination of the trial due to external influences may be an explanation as to why the data concludes that there appears to be no difference between the two study groups ${ }^{31}$. However, the authors need to be commended upon their efforts in recruiting suitable patients, when one has to consider the multiple agencies involved in the pre-hospital management of patients prior to arrival at the hospital.

The article from Townsville Hospital ${ }^{28}$ mentions some success in patients who have received $\mathrm{MgSO}_{4}$ and that medical treatment was consistent with the Irukandji Taskforce Guidelines. 
However it lacks specific details such as; the severity of the syndrome, quantity of opiates received prior to receiving $\mathrm{MgSO}_{4}$, specific vital signs and pain score. It also discusses the limited knowledge in nursing staff with regards to the signs and symptoms of IS, the underlying pathophysiology and the appropriate monitoring for patients who are receiving $\mathrm{MgSO}_{4}$.

QAS initial success ${ }^{27}$ may be due to a number of factors, including early pain management, which is reported to have a greater success in controlling pain in the acute setting ${ }^{32}$. Morphine is readily available to all QAS paramedics, and $\mathrm{MgSO}_{4}$ has been shown to increase the analgesic effects of morphine in animal models ${ }^{33}$. The relatively high dose of $\mathrm{MgSO}_{4}$ in the QAS protocol may also be a factor. However this letter fails to mention specific details such as blood pressure and pain score.

A multi-agency randomised controlled trial using standardised diagnostic definitions and treatment regimens is needed to establish whether $\mathrm{MgSO}_{4}$ has a role in managing this debilitating syndrome. Involving all prehospital agencies and receiving facilities will enable an overall control in drug use and dosage but will also allow for maximum patient capture. Such a trial should consider a relatively higher dose of $\mathrm{MgSO}_{4}$ over previous trials and documented cases of recrudescence of symptoms which suggest a dose response relationship.

There also needs a greater understanding on causative species and their geographic localities. Venom variability amongst species and within the same species, such as between juveniles and mature specimens or seasonal and/or geographical changes may affect the response of IS to magnesium. This would require the combined efforts of the scientific communities and medical facilities, enabling a combined effort to produce and maintain management protocols based on current research and understanding.

The retrieval and management of IS patients costs the health services in northern Australia approximately AU\$1-3 million per year ${ }^{14}$ and with potentially added indirect costs through loss of tourism. The publicity of the two IS related fatalities in Queensland, Australia in 2002 cost the government an estimated AU\$65 million in lost tourism revenue and work time ${ }^{34}$.

Furthermore a recognised descriptive definition of IS needs to be devised, that is accepted not only within the medical society but also within the scientific community. Fenner ${ }^{13}$ and Carrette ${ }^{14}$ list in detail the variable signs and symptoms that can arise in IS, highlighting the need for an accepted definition. This will reduce the confusion of 'what is IS' or the use of the term 'unknown marine toxidrome' and will help identify the true scope this syndrome has along the popular tropical and subtropical regions of the world.

At the time of publication a multicentre, prehospital and Emergency department randomised controlled trial has received QEMRF funding and ethics approval for Townsville 
Hospital, Mackay Base Hospital, Cairns Hospital, Care Flight Retrieval Medicine and QAS (C. Gibbs 2015, pers. Comm., $23^{\text {rd }}$ December).

\section{Limitations}

Irukandji is an Australian term and as such searching data bases might have missed similar syndromes from elsewhere around the world, however we do not think we have missed any other foreign language terminology. The significant variance in magnesium dosage and the limited recording of patient outcomes in some papers confines the limits of this review as does the small number of articles in the area.

\section{Conclusion}

This systematic review found that there is a lack of clinical trial evidence to support the use of $\mathrm{MgSO}_{4}$ in IS. Current use in practice is based upon efficacy reported in case series. Further randomised trials are necessary to define the role of $\mathrm{MgSO} 4$ in the management of this envenoming. The reporting of recrudescence of symptoms with reduction of dose does suggest a dose response relationship. The definitions of IS and study treatment protocols vary markedly, which is a limitation of the published data.

Until such time as a multi-agency RCT is undertaken, IS patients should continue to be managed as per local protocols and policies. The use of $\mathrm{MgSO}_{4}$ should be considered where other treatment fails to produce clinically adequate analgesia and/or reduction in hypertension.

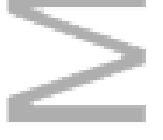

\section{L \\ References}

1. Fenner PJ, Hadok JC. Fatal envenomation by jellyfish causing Irukandji syndrome. Medical Journal of Australia 2002; 177(7): 362-3.

2. Pereira $\mathrm{P}$, Barry J, Corkeron $\mathrm{M}$, Keir $\mathrm{P}$, Little $\mathrm{M}$, Seymour J. Intracerebral hemorrhage and death after envenoming by the jellyfish Carukia barnesi. Clinical toxicology 2010; 48(4): 390-2.

3. Barnes JH. CAUSE AND EFFECT IN IRUKANDJI STINGINGS. Med J Aust 1964; 1: 897-904.

4. Southcott R. Studies on Australian Cubomedusae, Including a New Genus and Species Apparently Harmful to Man. Marine and Freshwater Research 1956; 7(2): 254-80.

5. Gershwin L-A. Two new species of box jellies (Cnidaria: Cubozoa: Carybdeida) from the central coast of Western Australia, both presumed to cause Irukandji syndrome. Records of the Western Australian Museum 2014; 29(1): 10-9. 
6. Yoshimoto CM, Yanagihara AA. Cnidarian (coelenterate) envenomations in Hawai'i improve following heat application. Transactions of the Royal Society of Tropical Medicine and Hygiene 2002; 96(3): 300.

7. de Pender AMG, Winkel KD, Ligthelm RJ. A probable case of Irukandji syndrome in Thailand. Journal of travel medicine 2006; 13(4): 240-3.

8. Grady JD, Burnett JW. Irukandji-Like Syndrome in South Florida Divers. Ann Emerg Med 2003; 42(6): 763-6.

9. Old $\mathrm{HH}$. Additional report of several cases with unusual symptoms caused by some unknown variety of jellyfish. United States Naval Medical Bulletin 1912; 6: 377-80.

10. Lord RE, Wilks SLB. A case of jelly-fish sting simulating an acute abdomen. Lancet 1918; 192(4960): 390.

11. Cheng AC, Winkel KD, Hawdon GM, McDonald M. Irukandji-like syndrome in Victoria. Australian and New Zealand Journal of Medicine 1999; 29(6): 835-.

12. Fenner PJ. Dangerous Australian box jellyfish. South Pacific Underwater Medicine Society Journal 2005; 35(2): 76-83.

13. Carrette TJ, Underwood AH, Seymour JE. Irukandji syndrome: a widely misunderstood and poorly researched tropical marine envenoming. Diving and hyperbaric medicine 2012; 42(4): 214-23.

14. Tibballs J, Li R, Tibballs HA, Gershwin LA, Winkel KD. Australian carybdeid jellyfish causing " Irukandji syndrome". Toxicon 2012; 59(6): 617-25.

15. Tibballs J. Australian venomous jellyfish, envenomation syndromes, toxins and therapy. Toxicon 2006; 48(7): 830-59.

16. Tibballs J, Hawdon G, Winkel K. Mechanism of cardiac failure in Irukandji syndrome and first aid treatment for stings [1]. Anaesthesia and Intensive Care 2001; 29(5): 552.

17. Fawcett WJ, Haxby EJ, Male DA. Magnesium: physiology and pharmacology. British journal of anaesthesia 1999; 83(2): 302.

18. Musso CG. Magnesium metabolism in health and disease. International Urology and Nephrology 2009; 41(2): 357-62.

19. Corkeron MA. Magnesium infusion to treat Irukandji syndrome. Medical Journal of Australia 2003; 178(8): 411.

20. McCullagh N, Pereira $P$, Cullen $P$, et al. Randomised trial of magnesium in the treatment of Irukandji syndrome. Emergency Medicine Australasia 2012; 24(5): 560-5.

21. Australian Resuscitation Council. Worksheet to support the development of guidelines. Melbourne, Australia: Australian Resusciation Council; 2008. p. 13.

22. Little M. Failure of magnesium in treatment of Irukandji syndrome. Anaesth Intensive Care 2005; 33(4): 541-2.

23. Corkeron M, Pereira P, Makrocanis $\mathrm{C}$. Early experience with magnesium administration in Irukandji syndrome. Anaesthesia and Intensive Care 2004; 32(5): 666-9.

24. Macrokanis CJ, Hall NL, Mein JK. Irukandji syndrome in northern Western Australia: An emerging health problem. Medical Journal of Australia 2004; 181(11-12): 699-702.

25. Mclver LJ, Tjhung IG, Parish ST, Derkenne RC, Kippin AN. Irukandji sydrome in the Torres

Strait: a series of 8 cases. Wilderness Environ Med 2011; 22(4): 338-42.

26. Nickson CP, Waugh EB, Jacups SP, Currie BJ. Irukandji syndrome case series from Australia's Tropical Northern Territory. Annals of emergency medicine 2009; 54(3): 395-403.

27. Rathbone J, Quinn J, Rashford S. Response to 'Randomised trial of magnesium in the treatment of Irukandji syndrome'. Emergency Medicine Australasia 2013; 25(1): 97-8. 
28. Clarkson RSG. Irukandji Syndrome: A critique of current nursing management at The Townsville Hospital Emergency Department. Australasian Emergency Nursing Journal; 13(3): 78-88. 29. Pereira P. Irukandji Taskforce Guidelines for the Emergency Management of Irukandji Syndrome. Available from URL: http://archiverubiconfoundationorg/xmlui/handle/123456789/9372; (Accessed 16th June 2014).

30. Queensland Ambulance Service. Clinical Practice Manual; Drug Therapy Protocols pdf. https://ambulanceqldgovau/clinicalhtm/ 2006; (Accessed 16th June 2014).

31. Pocock SJ. When To Stop A Clinical Trial. BMJ: British Medical Journal 1992; 305(6847): $235-$ 40.

32. Carr DB, Goudas LC. Acute pain. The Lancet 1999; 353(9169): 2051-8.

33. Begon S, Pickering G, Eschalier A, Dubray C. Magnesium increases morphine analgesic effect in different experimental models of pain. Anesthesiology 2002; 96(3): 627-32.

34. Gershwin LA, de Nardi M, Winkel KD, Fenner PJ. Marine stingers: Review of an underrecognized global coastal management issue. Coastal Management 2010; 38(1): 22-41.

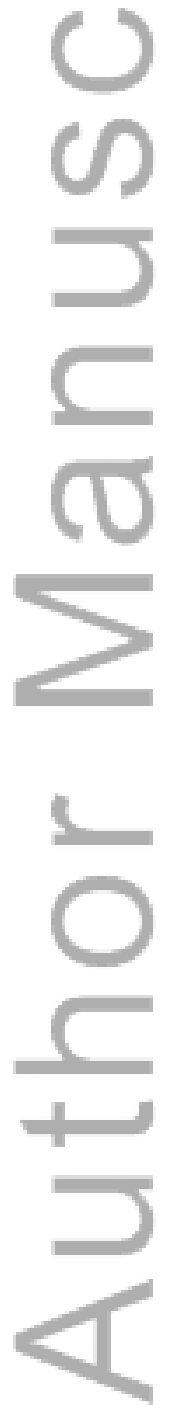

This article is protected by copyright. All rights reserved. 
Figure 1. Search strategy and results
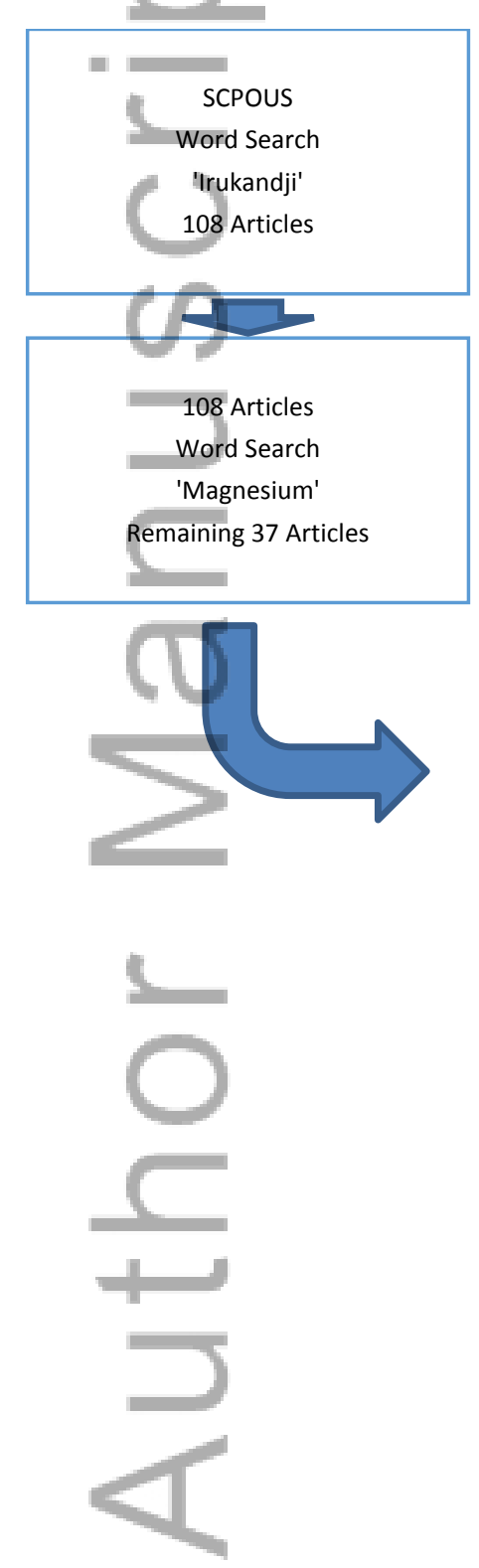
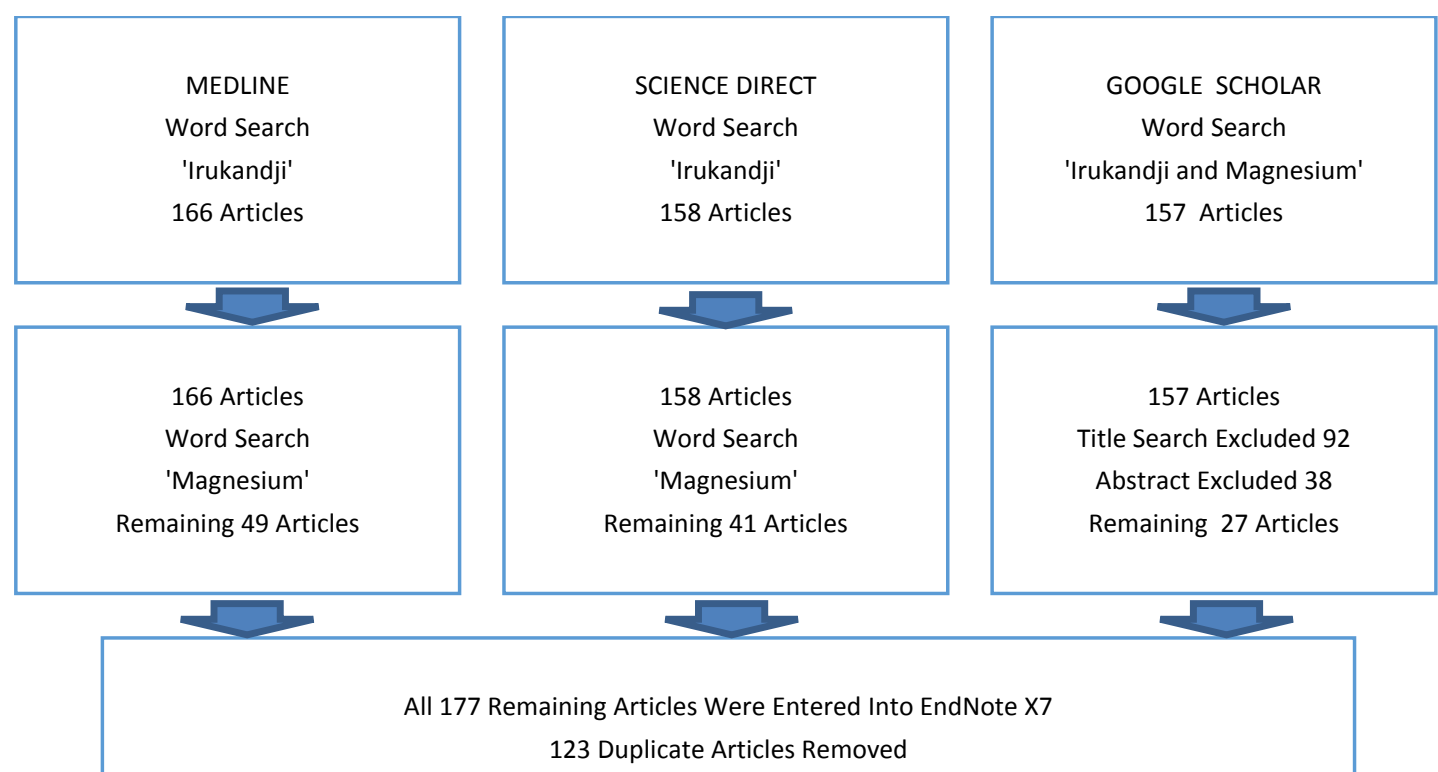

All 177 Remaining Articles Were Entered Into EndNote X7

123 Duplicate Articles Removed

A Further 45 Removed After Reading The Full Article

A Total of 9 Articles Remaining For Review
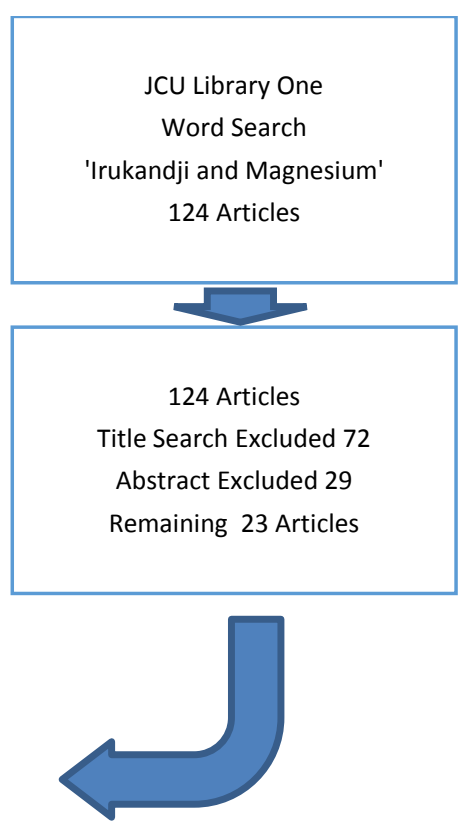
Table 1 Level of Evidence.

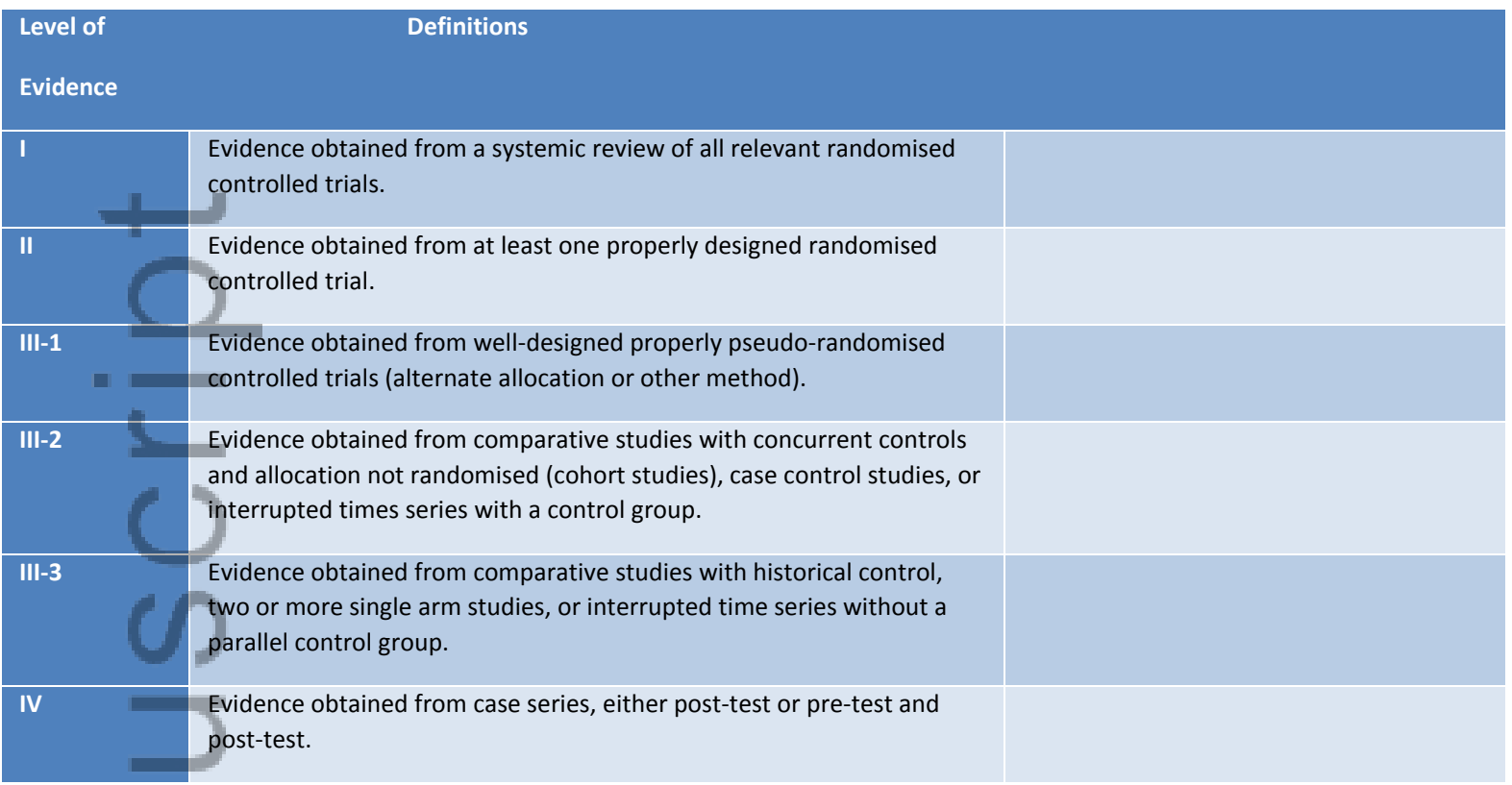

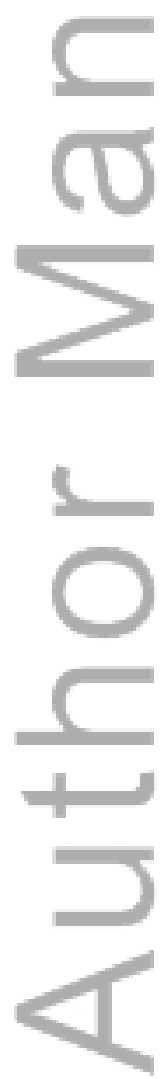

This article is protected by copyright. All rights reserved. 
Table 2 Summary of the 9 Reviewed Articles.

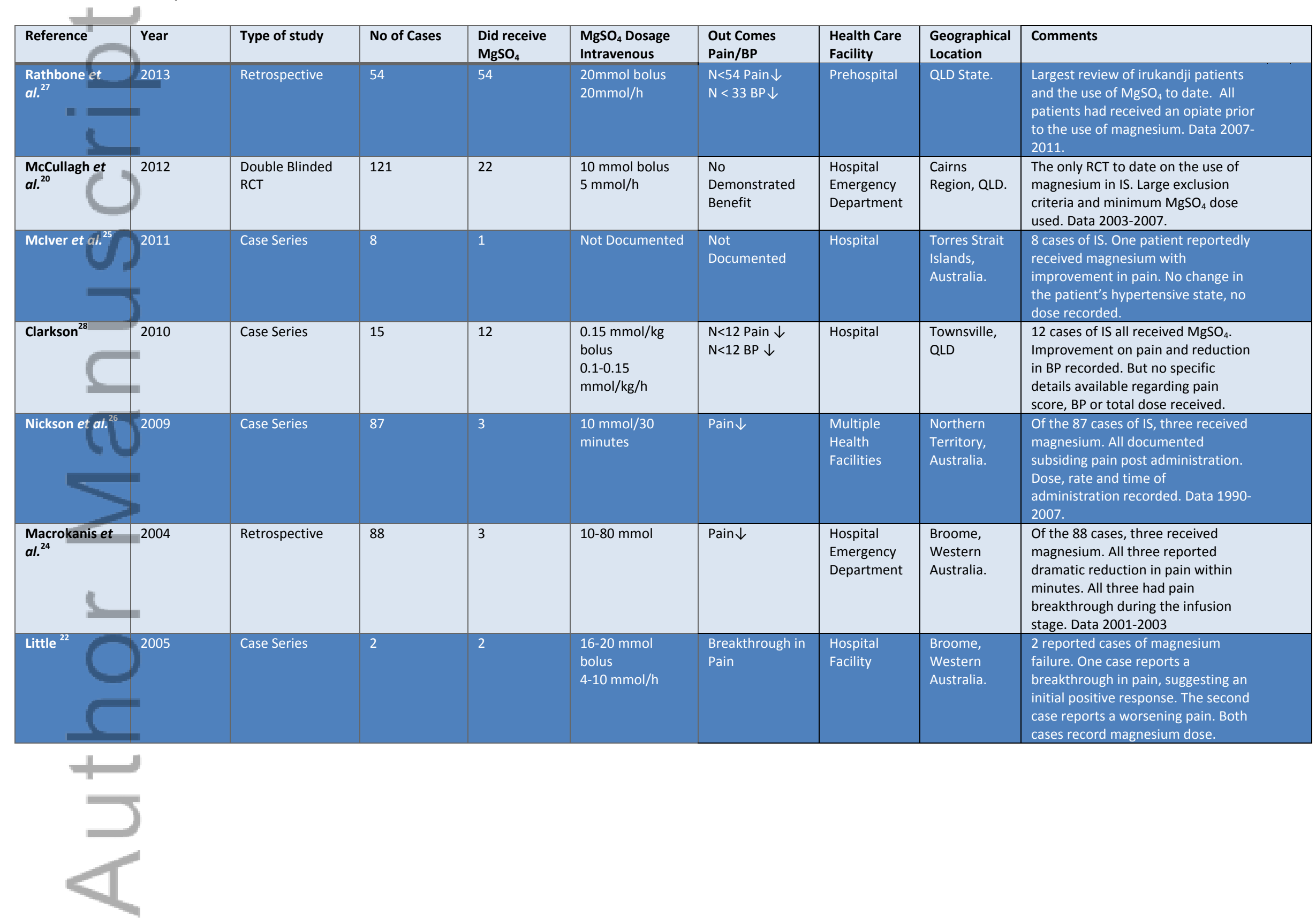

This article is protected by copyright. All rights reserved. 


\begin{tabular}{|c|c|c|c|c|c|c|c|c|c|}
\hline $\begin{array}{l}\text { Corkeron et } \\
\text { al. }^{23}\end{array}$ & 2004 & $\begin{array}{l}\text { Non Randomized } \\
\text { Case Series }\end{array}$ & 13 & 10 & $\begin{array}{l}10-20 \mathrm{mmol} \\
\text { bolus } \\
20 \mathrm{mmol} / \mathrm{h}\end{array}$ & $\begin{array}{l}\text { Pain } \downarrow \\
\text { BP } \downarrow\end{array}$ & $\begin{array}{l}\text { Hospital } \\
\text { Facility }\end{array}$ & $\begin{array}{l}\text { Townsville } \\
\text { QLD, } \\
\text { Australia }\end{array}$ & $\begin{array}{l}\text { Of the } 13 \text { cases, three where } \\
\text { excluded due to insufficient details. } \\
3 \text { cases reported from Broome, WA, } \\
\text { the remaining from } \mathrm{N} \text { QLD. Detailed } \\
\text { patients outcomes recorded i.e. Pain } \\
\text { score, Blood pressure, } \mathrm{MgSO}_{4} \text { dose. }\end{array}$ \\
\hline $\begin{array}{l}\text { Corkeron et } \\
\text { al. } .^{19}=\mathrm{a}\end{array}$ & 2003 & Case Series & 1 & 1 & $\begin{array}{l}10 \mathrm{mmol} \text { bolus } \\
5 \mathrm{mmol} / \mathrm{h}\end{array}$ & $\begin{array}{l}\text { Pain } \downarrow \\
\text { BP } \downarrow\end{array}$ & $\begin{array}{l}\text { Hospital } \\
\text { Facility }\end{array}$ & $\begin{array}{l}\text { Townsville, } \\
\text { Australia }\end{array}$ & $\begin{array}{l}\text { First recorded case of IS receiving } \\
\text { magnesium. } 2003 \text { data. }\end{array}$ \\
\hline
\end{tabular}

3 
Table 3 Methodological Quality of Studies

\begin{tabular}{|c|c|c|c|c|c|c|c|}
\hline \multicolumn{8}{|c|}{ Methodological Quality of Studies } \\
\hline & \multicolumn{2}{|c|}{$\begin{array}{c}\text { Good } \\
\text { The methodological quality of } \\
\text { the study is high with the } \\
\text { likelihood of any significant } \\
\text { bias being minimal }\end{array}$} & $\begin{array}{r}\text { The meth } \\
\text { the stud } \\
\text { the pot } \\
\text { bi }\end{array}$ & $\begin{array}{l}\text { quality of } \\
\text { ble with } \\
\text { nificant }\end{array}$ & \multicolumn{2}{|c|}{$\begin{array}{c}\text { Poor } \\
\text { The methodological Quality of } \\
\text { the study is weak, possessing } \\
\text { considerable and significant } \\
\text { biases }\end{array}$} & \\
\hline Supportive & $=$ & & & & & $\begin{array}{c}\text { Corkeron } \\
2003, \\
\text { Corkeron } \\
2004, \\
\text { Macrokanis } \\
2004, \\
\text { Nickson } \\
2009, \text { Mclver } \\
2011, \\
\text { Rathbone } \\
2013\end{array}$ & \\
\hline Negative & & $\begin{array}{l}\text { McCullagh } \\
2012\end{array}$ & & & & Little 2005 & \\
\hline $\begin{array}{l}\text { Level of } \\
\text { Evidence }\end{array}$ & & II & III-1 & III-2 & III-3 & IV & Other \\
\hline
\end{tabular}

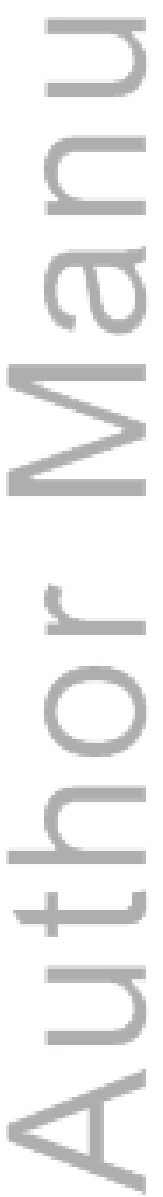

This article is protected by copyright. All rights reserved. 
Table 4 RCT Summary Overview

\begin{tabular}{|l|l|l|}
\hline \multicolumn{3}{|c|}{ Overview of the Results of the 39 RCT patients with Irukandji Syndrome } \\
\hline & Placebo & Magnesium \\
\hline $\begin{array}{l}\text { Mean Morphine equivalent dose (mg) once entry into } \\
\text { trial. }\end{array}$ & 53 & 50 \\
\hline Median Length of Stay (h) & 19 & 20.7 \\
\hline Mean Peak Pulse (bpm) & 101 & 101 \\
\hline Mean Peak Troponin I Level (mcg/L) & 2.4 & 8.3 \\
\hline Mean Percentage MAP rise & 138 & 135 \\
\hline Mean Peak CK (U/L) & 499 & 537 \\
\hline Serum Mg Level (mmol/L) & 1.03 & 1.83 \\
\hline
\end{tabular}

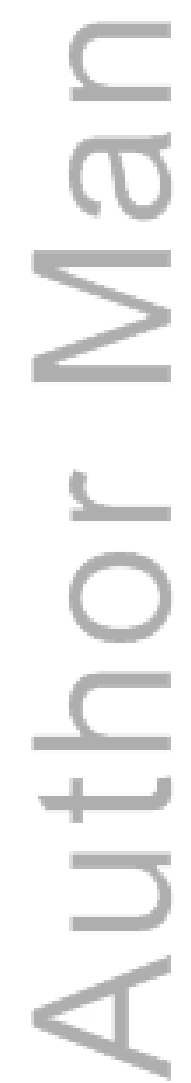

This article is protected by copyright. All rights reserved. 


\section{University Library}

\section{- M M N E R VA A gateway to Melbourne's research publications}

Minerva Access is the Institutional Repository of The University of Melbourne

Author/s:

Rathbone, J;Franklin, R;Gibbs, C;Williams, D

Title:

Review article: Role of magnesium sulphate in the management of Irukandji syndrome: A systematic review

Date:

2017-02-01

Citation:

Rathbone, J., Franklin, R., Gibbs, C. \& Williams, D. (2017). Review article: Role of magnesium sulphate in the management of Irukandji syndrome: A systematic review. EMERGENCY MEDICINE AUSTRALASIA, 29 (1), pp.9-17. https:// doi.org/10.1111/1742-6723.12694.

Persistent Link:

http://hdl.handle.net/11343/291851 